\section{Case 2}

A 74-year-old woman weighing $48 \mathrm{~kg}$ was admitted for a simple mastectomy 14 months after advanced carcinoma of the breast had been treated by radiotherapy. She was in good general health, her only complaint being dyspnoea on exertion. Examination showed a pansystolic murmur, which was attributed to mild mitral incompetence. Arterial pressure was 180 $65 \mathrm{~mm} \mathrm{Hg}$. There was no evidence of cardiac failure, but an electrocardiogram contained some evidence of myocardial ischaemia. Haemoglobin was $12 \cdot 1 \mathrm{~g} / \mathrm{dl}$; serum urea and electrolyte concentrations were normal. Drug treatment at the time of surgery was digoxin $0.25 \mathrm{mg}$ and frusemide $40 \mathrm{mg}$ once daily and one potassium chloride (Slow-K) tablet thrice daily.

The patient was premedicated with morphine $5 \mathrm{mg}$ and atropine $0.6 \mathrm{mg}$ intramuscularly two hours before surgery. Anaesthesia was induced with intravenous thiopentone $150 \mathrm{mg}$ and suxamethonium $50 \mathrm{mg}$, and an $8 \mathrm{~mm}$ cuffed Oxford endotracheal tube was passed. When muscle tone returned she was given intravenous alcuronium $10 \mathrm{mg}$ and fentanyl $0.075 \mathrm{mg}$ and ventilated with nitrous oxide and oxygen using an East-Radcliffe ventilator in the "circle-without-absorber" mode, with a fresh-gas flow of $61 / \mathrm{min}$ and a tidal volume of $700 \mathrm{ml}$. Surgery lasted 45 minutes, at the end of which atropine $0.6 \mathrm{mg}$ and neostigmine $2.5 \mathrm{mg}$ were given. She received no othe drugs. Recovery was uneventful, and on return to the ward she conducted a normal conversation and was aware of her surroundings.

Three hours later she became increasingly drowsy with a slow respiratory rate and needed a nurse to sit with her; the anaesthetist could not accoun for the change in her level of consciousness. No treatment was given and she eventually recovered. No postoperative medication had been given.

\section{Case 3}

A 46-year-old woman weighing $60 \mathrm{~kg}$ was admitted for elective cholecystectomy. She had cervical spondylosis, which restricted neck movement, but was otherwise in good health. Papaveretum $15 \mathrm{mg}$ and hyoscine $0.3 \mathrm{mg}$ were given intramuscularly one-and-a-quarter-hours preoperatively. Anaesthesia was induced with intravenous thiopentone $240 \mathrm{mg}$, pancuronium $6 \mathrm{mg}$, and fentanyl (Sublimaze) $0.5 \mathrm{mg}$, and the patient was ventilated by means of a Nuffield ventilator and Bain anaesthetic circuit with a fresh-gas flow of $6 \mathrm{l} / \mathrm{min}$. Pancuronium $2 \mathrm{mg}$ and fentanyl $0.1 \mathrm{mg}$ were given during the one-and-a-quarter-hour operation, at the end of which she received atropine $1.2 \mathrm{mg}$ and neostigmine $2.5 \mathrm{mg}$. She was extubated when spontaneous breathing resumed.

In the recovery room she talked rationally, and reversal of the neuromuscular blockade was clinically adequate. Thirty minutes later she became cyanosed and respiratory arrest occurred. Ventilation of the lungs with oxygen by facemask was instituted and intravenous naloxone $0.4 \mathrm{mg}$ given. She awoke immediately and respiration returned to normal.

\section{Comment}

Some respiratory depression may be expected in the immediate postoperative period. This may be due either to central depression produced by opiates, ${ }^{1}$ barbiturates, or volatile anaesthetic agents or to a peripheral mechanism such as inadequate reversal of neuromuscular blockade or reduction in chest-wall compliance. ${ }^{1}$ Investigation of the extent to which opiates produce respiratory depression has shown that when the $\mathrm{CO}_{2}$ response curve is used as an index fentanyl has a significant depressant effect. ${ }^{2}$ Most workers have found consistent decreases in the slope of the curve, although some have found only a parallel displacement.

Fentanyl is widely regarded as a short-acting opiate, but at typical dosage its respiratory depressant action lasts for at least four hours, and the magnitude and duration of effect are comparable to those of an equianalgesic dose of morphine." A recent study ${ }^{3}$ found no significant differences in the intraoperative duration of action of equianalgesic doses of morphine, fentanyl, and phenoperidine and in the duration of postoperative analgesia. There is little evidence that fentanyl is a short-acting drug, although Foldes ${ }^{4}$ commented on the transience of the hypnotic as opposed to the analgesic effect when compared with that of other opiates, which may well be responsible for the generally held impression of a short duration of action.

Respiratory depression in the present patients was almost certainly precipitated by opiates, as in two cases the response to naloxone, a specific narcotic antagonist, was rapid and complete. Nevertheless, the intervening period of apparent recovery requires explanation. Becker $e t a l^{5}$ showed that fentanyl has a biphasic effect on the ventilatory response to $\mathrm{CO}_{2}$. In 26 patients respiratory depression (manifest as a decrease in slope of the $\mathrm{CO}_{2}$ response curve) was maximal shortly after intravenous administration of the drug and then decreased steadily. Continued monitoring showed a second phase of respiratory depression, occurring when the patient was in the recovery room and maximal about 160 minutes after the last dose of narcotic. It was suggested that either varying levels of stimulation during the recovery period alter the response to $\mathrm{CO}_{2}$ or fentanyl, like pethidine, ${ }^{6}$ is secreted into the stomach to be reabsorbed on transit to the jejunum. Serum concentrations of the drug were not measured during the study, so the authors could not distinguish between these two possibilities. The pattern of depression seen was principally a decreased slope of $\mathrm{CO}_{2}$ response without associated hypercapnia. The authors pointed out the possible risk imposed by an otherwise minor degree of airway obstruction in a patient who has little ventilatory response to such a $\mathrm{CO}_{2}$ challenge.

Possibly, such an airway obstruction occurred in two of our patients, since case 1 had pharyngeal oedema and case 3 had cervical spondylosis. This together with an insensitivity to a rising alveolar $\mathrm{PCO}_{2}$ may have trapped them in a cycle of increasingly inadequate ventilation associated with increasing $\mathrm{CO}_{2}$ narcosis.

We thank Mr T J S Patterson, consultant plastic surgeon, Churchill Hospital, Oxford, and Dr H J McQuay and Dr N I Newton, anaesthetic registrars, Radcliffe Infirmary, Oxford, for permission to report details of patients under their care.

${ }^{1}$ Knill, R, et al, Canadian Anaesthetists' Society fournal, 1976, 23, 449.

2 Rigg, J R A, and Goldsmith, C H, Canadian Anaesthetists' Society fournal, 1976, 23, 370 .

${ }^{3}$ Holmes, C McK, British fournal of Anaesthesia, 1976, 48, 907.

${ }^{4}$ Foldes, F F, Shiffman, H P, and Kronfeld, P P, Anesthesiology, 1970, 33, 35.

5 Becker, L D, et al, Anesthesiology, 1976, 44, 291.

6 Trudnowski, R J, and Gessner, T, Abstracts of Scientific Papers, Annual Meeting of the American Society of Anesthesiologists, p 327.1975.

(Accepted 10 November 1977)

Nuffield Department of Anaesthetics, Radcliffe Infirmary, Oxford OX2 6HE

A P ADAMS, PHD, FFARCS, consultant ánaesthetist and clinical lecturer D A PYBUS, FFARCS, lecturer in anaesthesia

\section{Effect of quinidine on plasma concentrations of digoxin}

Plasma concentrations of digoxin and quinidine were extracted in 12 patients admitted for cardioversion of atrial fibrillation or flutter. They had been receiving digoxin for at least four weeks and the treatment was continued in hospital. After a loading dose of quinidine sulphate (0.6-0.8 g depending on body weight) maintenance doses of quinidine were given as Kinidin Durules (each tablet containing $250 \mathrm{mg}$ quinidine bisulphate, equivalent to $200 \mathrm{mg}$ quinidine sulphate), three tablets twice daily. Blood samples were taken 12-hourly over the next three to five days. Quinidine concentrations were determined by a modified version of Cramér and Isaksson's method, ${ }^{1}$ and digoxin concentrations by radioimmunoassay with commercial kits obtained

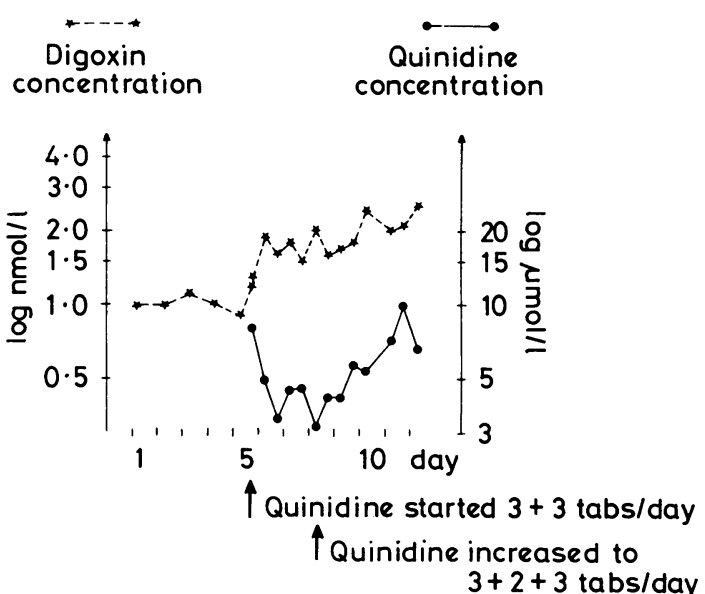

Plasma digoxin and quinidine concentrations in one patient. Conversion: SI to traditional units-Plasma digoxin: $1 \mathrm{nmol} /$ $1 \approx 0.8 \mathrm{ng} / \mathrm{ml}$. Plasma quinidine: $1 \mu \mathrm{mol} / 1 \approx 0.3 \mu \mathrm{g} / \mathrm{ml}$. 
from Schwartz-Mann and Clinical Assay (the results with these two kits showed close correlation). Steady-state plasma quinidine concentrations ranged from 4.2 to $12.7 \mu \mathrm{mol} / 1(1.3$ to $3.8 \mu \mathrm{g} / \mathrm{ml})$ with an average of 7.0 $\mu \mathrm{mol} / 1(2 \cdot 1 \mu \mathrm{g} / \mathrm{ml})$.

All 12 patients showed a rise in plasma digoxin concentrations when quinidine was given (mean value $1.1 \mathrm{nmol} / 1(0.85 \mathrm{ng} / \mathrm{ml})$ before quinidine, and $2.0 \mathrm{nmol} / 1(1.6 \mathrm{ng} / \mathrm{ml})$ after quinidine). Five determinations of plasma digoxin were made in each patient after the start of quinidine treatment. One of the six patients whose plasma concentrations rose above the therapeutic range on one or more occasions developed symptoms of digitalis intoxication. In the first four patients the digoxin concentration was measured only once before adding quinidine, whereas more determinations were performed in the remaining patients to check that they had been taking the tablets as prescribed and that the digoxin concentrations represented steady-state values. The figure shows the drug concentration curves in the patient whose concentrations were measured most often.

The possibility of interference by quinidine or a metabolite of quinidine in the digoxin assay was excluded by the following control studies. (1) Digoxin was sought in the plasma of patients undergoing cardioversion in the same way while not on digoxin treatment: no measurable concentration were found. (2) Quinidine was added to samples of whole blood from patients on digoxin alone until the quinidine concentrations fell within the therapeutic range: this did not affect the digoxin concentrations. (3) Digoxin added to blood samples from one group of patients who were taking quinidine alone, and from another group of patients not taking quinidine: the digoxin concentrations did not differ between the two groups.

\section{Comment}

The mechanism of this drug interaction is under investigation particularly the possibility that quinidine affects the binding of digoxin in tissues. Until the clinical importance of the phenomenom is understood the increased risk of digitalis intoxication should be considered in patients taking this combination of drugs.

${ }^{1}$ Cramér, G, and Isaksson, B, Scandinavian fournal of Clinical and Labora tory Investigation, 1963, 15, 553.

(Accepted 6 December 1977)

Karolinska Institute, Huddinge University Hospital, S-141 86Huddinge, Sweden

GUNNAR EJVINSSON, MD, junior registrar

\section{SHORT REPORTS}

\section{Biochemical changes associated with intractable pain}

The "holy grail" of most medical practitioners who specialise in intractable pain is the objective assessment of pain. Various biochemical changes have been suggested ${ }^{1-4}$ : terminal cancer with intractable pain has been associated with metabolic alkalosis, ${ }^{1}$ and, conversely, $\mathrm{Lindah}^{2}$ suggested that acidosis was either the cause or the result of intractable pain. Some years earlier he had described a condition that he called "varalgia," in which acidosis was the concomitant of intractable pain, and if these patients were treated with an acid-free diet the pain was relieved.

Lascelles $e t a l^{3}$ measured the plasma cortisol concentration in a diurnal variation in two groups of patients with intractable pain, the cause of which was organic in one group and psychogenic in the other. There were no significant differences in the plasma cortisol concentration in these two groups; indeed, the results were within the normal range throughout the day. Plasma cholesterol and beta-lipoprotein concentrations have fallen after upper abdominal surgery ${ }^{4}$ and the fall in these two criteria postoperatively could be equated with a decrease in pain. The plasma cholesterol and beta-lipoprotein concentrations, however, were within a normal range.

\section{Patients, methods, and results}

The 52 patients admitted to the pain relief unit, Abingdon, with intractable pain* were 32 women and 20 men with a mean age of 52.7 years (range 16-82) Fourteen had low back pain, 21 had cancer of various sites, and 17 sufferedeo from various conditions such as arthritis, postherpetic neuralgia, and phantom limb.

On admission all patients had a full physical examination and any who failed Allen's test for the adequacy of the ulnar circulation to the hand were excluded from the study. After informed consent, the radial artery of the non-dominant wrist was cannulated percutaneously under local anaesthesia. $\mathrm{PaO}_{2}, \mathrm{PaCO}_{2}$, and $\mathrm{pH}$ were measured with an electrode system (Radiometero PHM 27) every two hours from 0800 to 2200 . Blood samples were taken for routine haematological (haemoglobin and white cell count etc) and biochemical tests (electrolytes and sequential multiple analyses 12/60). In addi- $\overline{0}$ tion, 13 patients had blood drawn at 0900 for plasma cortisol estimations. ${ }^{3} 3$

Thirty of the 52 patients obtained pain relief after treatment. This was? assessed by asking the patient and confirmed by the withdrawal of analgesicso or a substantial reduction in the strength and amount needed. Only 10 of these 30 patients, however, were available for follow-up $\mathrm{PaO}_{2}, \mathrm{PaCO}_{2}$, and $\mathrm{pH}$ measurements. Repeat arterial cannulations were performed in seven of them, while the remaining three had a single arterial puncture.

The mean $\mathrm{PaO}_{2}, \mathrm{PaCO}_{2}$, and $\mathrm{pH}$ together with the diurnal range for each of these three groups are shown in the table. After successful treatment.

*Intractable pain was defined for this study as pain of at least one month's duration that had not responded to conventional treatment.

Diurnal mean and range of $\mathrm{PaO}_{2}, \mathrm{PaCO}_{2}$, and $p H$ for each clinical group and mean $\mathrm{PacO}_{2}$ and $p H$ after successful treatment

\begin{tabular}{|c|c|c|c|c|c|c|c|}
\hline & \multicolumn{6}{|c|}{ Diurnal mean and range of $\mathrm{PaO}_{2}, \mathrm{PaCO}_{2}$, and $\mathrm{pH}$ for each clinical group } & \multirow{3}{*}{$\begin{array}{l}\text { Normal range } \\
\text { at Oxford }\end{array}$} \\
\hline & \multicolumn{2}{|c|}{ Low back pain } & \multicolumn{2}{|c|}{ Cancer } & \multicolumn{2}{|c|}{ General } & \\
\hline & Mean & Range & Mean & Range & Mean & Range & \\
\hline $\begin{array}{l}\mathrm{PaO}_{2}(\mathrm{kPa}) \\
\mathrm{PaCO}_{2}(\mathrm{kPa}) \\
\mathrm{pH}\end{array}$ & $\begin{array}{c}13 \cdot 2 \\
4 \cdot 1 \\
7 \cdot 42\end{array}$ & $\begin{array}{c}7 \cdot 3-18 \cdot 4 \\
2 \cdot 6-5 \cdot 3 \\
7 \cdot 37-7 \cdot 46\end{array}$ & $\begin{array}{c}11 \cdot 6 \\
4 \cdot 1 \\
7 \cdot 42\end{array}$ & $\begin{array}{c}7 \cdot 1-16 \cdot 0 \\
2 \cdot 4-5 \cdot 5 \\
7 \cdot 33-7 \cdot 52\end{array}$ & $\begin{array}{c}12 \cdot 1 \\
4 \cdot 2 \\
7 \cdot 42\end{array}$ & $\begin{array}{c}8 \cdot 7-17 \cdot 5 \\
3 \cdot 0-5 \cdot 3 \\
7 \cdot 32-7 \cdot 49\end{array}$ & $\begin{array}{c}8 \cdot 0-16 \cdot 0 \\
4 \cdot 8-5 \cdot 9 \\
7 \cdot 36-7 \cdot 45\end{array}$ \\
\hline
\end{tabular}

\begin{tabular}{|c|c|c|c|c|c|c|}
\hline Sex & Age & Group & $\begin{array}{c}\text { Pretreatment } \\
\mathrm{PaCO}_{2}(\mathrm{kPa})\end{array}$ & $\begin{array}{c}\text { Post-treatment } \\
\mathrm{PaCO}_{2}(\mathrm{kPa})\end{array}$ & $\begin{array}{c}\begin{array}{c}\text { Pretreatment } \\
\mathrm{pH}\end{array} \\
\end{array}$ & $\begin{array}{c}\text { Post-treatment } \\
\mathrm{pH}\end{array}$ \\
\hline $\begin{array}{l}\mathrm{F} \\
\mathrm{F} \\
\mathrm{M} \\
\mathrm{F} \\
\mathrm{M} \\
\mathrm{M} \\
\mathrm{F} \\
\mathrm{F} \\
\mathrm{F} \\
\mathrm{M}\end{array}$ & $\begin{array}{l}56 \\
33 \\
49 \\
22 \\
64 \\
60 \\
34 \\
79 \\
73 \\
57\end{array}$ & $\begin{array}{l}\text { LBP } \\
\text { LBP } \\
\text { LBP } \\
\text { LBP } \\
\text { Cancer } \\
\text { Cancer } \\
\text { Cancer } \\
\text { Cancer } \\
\text { Cancer } \\
\text { Cancer }\end{array}$ & $\begin{array}{l}4 \cdot 6 \\
3 \cdot 6 \\
4 \cdot 3 \\
4 \cdot 0 \\
3 \cdot 9 \\
4 \cdot 0 \\
4 \cdot 4 \\
4 \cdot 2 \\
4 \cdot 5 \\
4 \cdot 1\end{array}$ & $\begin{array}{l}4 \cdot 8 \\
4 \cdot 5 \\
4 \cdot 8 \\
4 \cdot 6 \\
4 \cdot 9 \\
4 \cdot 8 \\
5 \cdot 0 \\
5 \cdot 0 \\
5 \cdot 1 \\
5 \cdot 0\end{array}$ & $\begin{array}{c}* \\
7 \cdot 43 \\
7 \cdot 40 \\
7 \cdot 43 \\
7 \cdot 41 \\
7 \cdot 43 \\
7 \cdot 44 \\
7 \cdot 41 \\
7 \cdot 45 \\
7 \cdot 43\end{array}$ & $\begin{array}{l}7 \cdot 46 \\
7 \cdot 42 \\
7 \cdot 41 \\
7 \cdot 38 \\
7 \cdot 40 \\
7 \cdot 43 \\
7 \cdot 43 \\
7 \cdot 42 \\
7 \cdot 44 \\
7 \cdot 41\end{array}$ \\
\hline
\end{tabular}

LBP $=$ Low back pain.

*No result owing to technical fault. 